\title{
PREPARATION OF LANGMUIR-BLODGETT FILMS OF A NOVEL AMPHIPHILIC POLYSILANE
}

\author{
Takahiro SEKI, Takashi TAMAKI, and Katsuhiko UENO \\ National Institute of Materials and Chemical Research, \\ 1-1 Higashi, Tsukuba, Ibaraki 305, JAPAN
}

\author{
Yuji TANAKA \\ Daikin Industries Ltd., \\ 1-1 Nishi, Hitotsuya, Settsu, Osaka 566, JAPAN
}

Polysilanes have recently attracted much attention due to their unique photosensitive properties attributed to the delocalized $\sigma$-electron in the Si backbone. Quite recently a couple of research groups have started investigation of Langmuir-Blodgett (LB) films of polysilanes.[1-3] We have started the LB study using amphiphilic polysilanes bearing ammonium moiety in the side chain.[2] These materials are prepared through the chemical modification of conventional polysilanes having a phenyl moiety. In this communication we wish to present a novel type of amphiphilic polysilane obtained from a copolymerized-type starting material. Synthesis of the polysilanes, monolayer behaviors at the air-water interface, and spectroscopic properties of transferred LB films are described.

Scheme 1 displays the synthetic route for the amphiphilic polysilane (1) in this study. The copolymer-type precursor polysilane was obtained by Wurtz-type coupling using the mixture of methyl( $\beta$-phenethyl)dichlorosilane and dihexyldichlorosilane. The polymer was chloromethylated and then quarternized with $\mathrm{N}, \mathrm{N}$-dimethyloctylamine.[2] The resulted ratio of the two components was determined by ${ }^{1} \mathrm{H}-\mathrm{NMR}$ and is shown in the scheme.
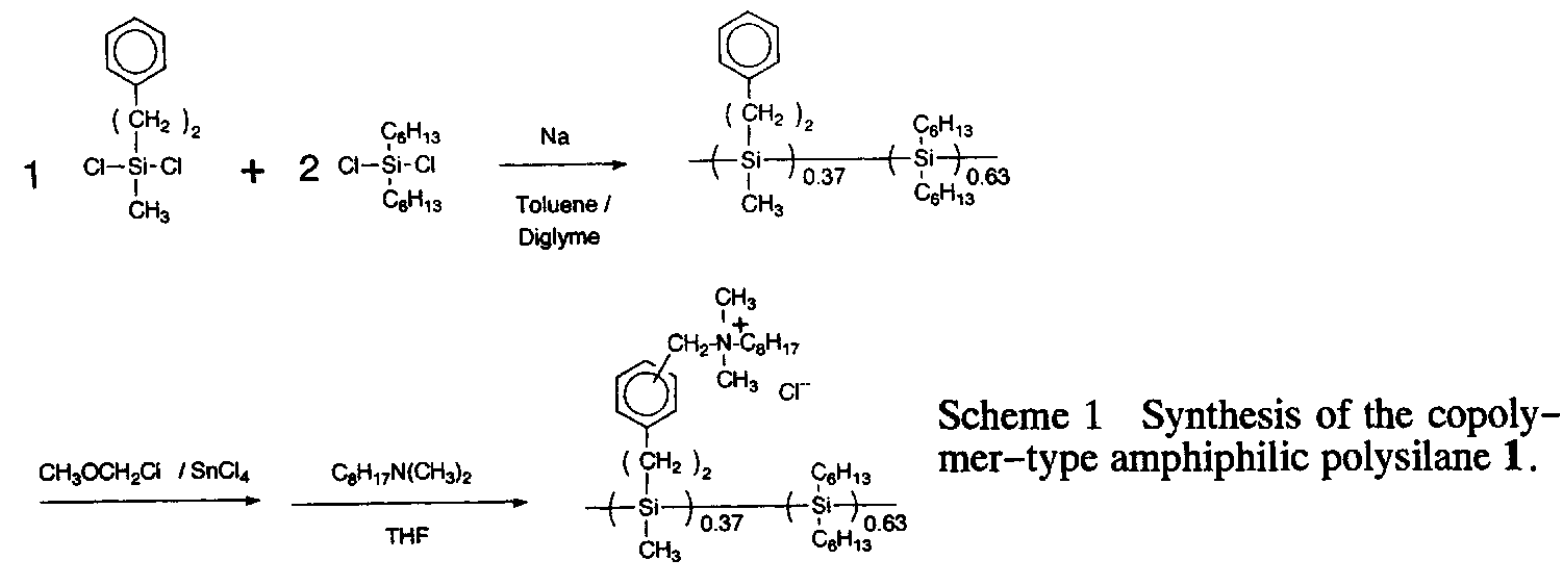

The surface pressure-area (per Si unit) isotherm of 1 was observed on distilled water and on $\mathrm{NaClO}_{4}\left(5 \times 10^{-4} \mathrm{M}\right)$ aq. solution. On $\mathrm{NaClO}_{4}$ solution the monolayer was more condensed (the 
limiting area = ca. $0.15 \mathrm{~nm}^{2}$ ) than on distilled water $\left(\mathrm{ca} .0 .2 \mathrm{~nm}^{2}\right)$, which is in consistent with the results with homopolymer-type amphiphilic polysilane 2 of the previous work.[2] The value of these area per Si unit obtained for 1 was obviously smaller than expected from the molecular structure. It is supposed that the dihexylsilane unit in the main chain without the hydrophilic group is squeezed out toward the air phase upon application of the surface pressure.

The monolayer of 1 on the water subphase could be transferred onto solid substrates at good ratios by the vertical dipping method. Figure 1 depicts the polarized UV absorption spectra of 21 LB layers on both sides of a quartz plate, the solid line being parallel to the dipping direction and the dotted line being perpendicular to it. This result implies that the polymer backbone preferentially aligns parallel to the dipping direction. The dichroic ratio (1.75) was evidently larger than that obtained with the previous homopolymer 2 (ca. 1.1).[2] The orientational order was the function of the number of deposition. The first single LB layer exhibited practically no in-plane orientation,

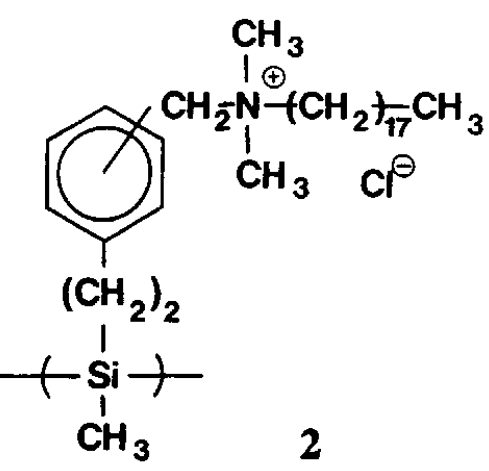
but accumulated depositions gave larger dichroic ratios (Fig. 2).

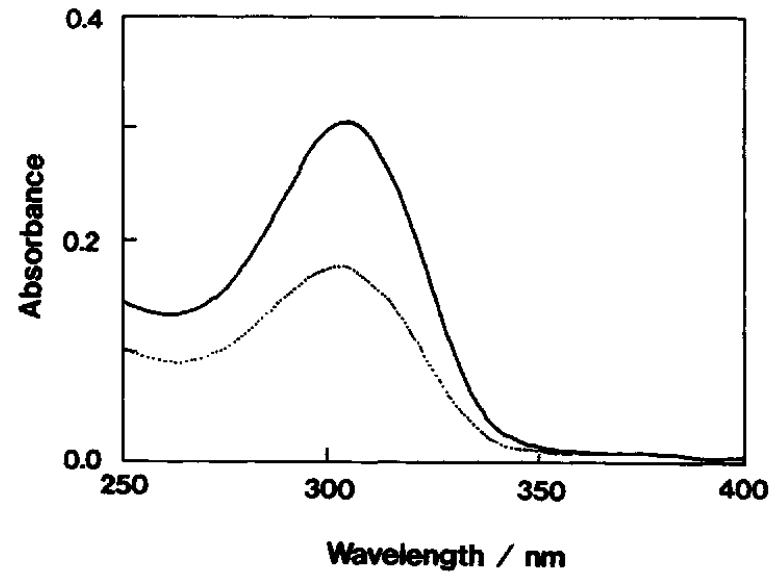

Fig. 1 Polarized UV spectra of 21-layered LB film of 1 on both side of a quartz plate. Solid and dotted lines indicate the spectra observed with polarized light parallel and perpendicular to the dipping direction, respectively.

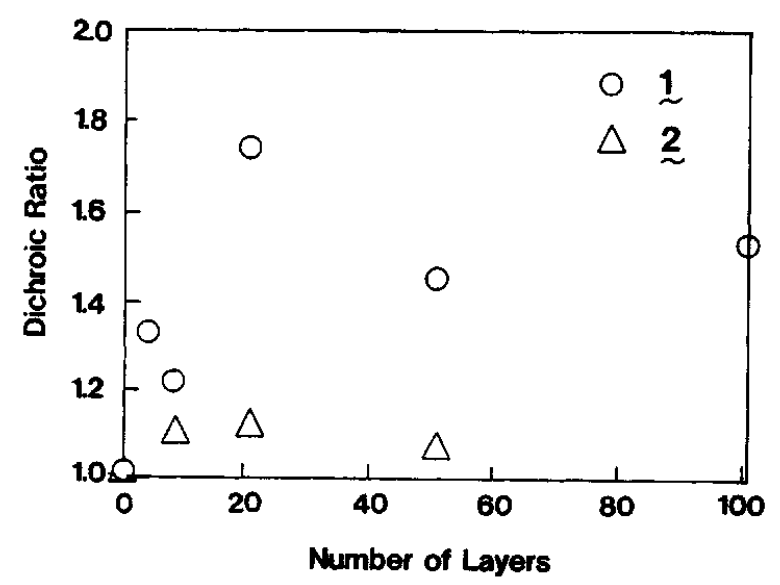

Fig. 2 Dichroic ratios of the LB films due to the backbone orientation as a function of the number of transferred layers.

\section{References}

1. F. W. Embs, G. Wegner, D. Neher, P. Albouy, R. D. Miller, C. G. Wilson, W. Schrepp, Macromolecules, 24 (1991) 5068.

2. T. Seki, T. Tamaki, and K. Ueno, Macromolecules, 25 (1992) 3825.

3. R. Kani, H. Yoshida, Y. Nakano, S. Murai, Y. Mori, S. Hayase, Polym. Prep. Jpn. 41 (1992) 3958. 